\title{
Morality, Rationality and Academic Dishonesty: A Partial Test of Situational Action Theory
}

\author{
John K. Cochran*
}

Department of Criminology, University of South Florida, 4202 E. Fowler Ave., SOC104, Tampa, FL 33620, USA

\begin{abstract}
This study uses self-report survey data from a sample of college students to provide a partial test of Wikström's situational action theory (2010a) by examining the extent, if any, to which the effects of perceptual deterrence on academic dishonesty are moderated by personal morality. The findings show that both personal morality and perceived certainty of formal sanctions are inversely associated with cheating; however, the deterrent effect of high perceived certainty of formal sanctions is not greater among those with weak moral prohibitions against cheating as predicted by Wikström and observed by Svensson (2015) in an earlier test of Wikström's situational action theory.
\end{abstract}

Keywords: Academic Dishonesty, Morality, Formal Deterrence, Situational Action Theory.

Recently, in a partial test of Wikström's situational action theory (2010a), Robert Svensson (2015) examined the extent to which perceptual deterrence and personal morality interact to explain adolescent offending. Based on self-report survey data from a sample of Swedish adolescents, he found that the effect of perceptual deterrence (i.e., the perceived likelihood of getting caught) on offending was dependent on an individuals' level of personal morality, such that the effect of perceptual deterrence was stronger for those individuals with lower levels of personal morality. Svensson's study was motivated by both (a) the equivocal findings that have emerged from an extensive body of research examining the effects of perceptual deterrence (Pratt, et al. 2006) and (b) the emergence of a smaller body of research examining the extent, if any, to which deterrent effects may be moderated by other individual characteristics, particularly low self-control (Cochran, Aleksa, and Sanders 2008; Gallupe and Baron 2014; Wright, et al. 2004).

Drawing from Wikström's situational action theory (2010a), Svensson (2015) asks, if the effects of perceptual deterrence on offending vary by low selfcontrol, might these effects also vary by other individual characteristics, such as personal morality? The present study attempts to replicate Svensson's (2015) study with self-report data regarding academic dishonesty derived from a sample of college students. Importantly, the present study employs behavior-specific indicators of perceptual deterrence and personal morality that closely match the forms of "offending" examined. The

${ }^{*}$ Address correspondence to this author at the Department of Criminology, University of South Florida, 4202 E. Fowler Ave., SOC104, Tampa, FL 33620, USA; Tel: (813) 974 - 9547; E-mail: cochran@usf.edu findings fail to reveal a significant interaction effect between perceptual deterrence and personal morality on academic dishonesty, though both personal morality and perceptual deterrence had significant independent/additive effects.

\section{WIKSTRÖM'S SITUATIONAL ACTION THEORY}

Wikström's situational action theory (2010a) is at once both remarkably parsimonious and deeply complex. On its surface, it offers a very parsimonious accounting for criminal/deviant behavior; it argues that offending is the outcome of how individuals confronting a situation perceive various behavioral alternatives as available, or not, for action and then make behavioral choices. This simple linkage of perceptions to choices is the situational mechanism that connects individuals and their environments to offending. However, as Wikström develops his theory more completely by peeling off this simple outer layer to his theory and delves more deeply into explicating all of the necessary logical linkages among his key theoretical constructs, the theory becomes both more complete and more complex. Too complex, perhaps, to be adequately tested by most existing data sources, including the data utilized in the present study. Because the present study does not and cannot fully test Wikström's theory and, instead, offers only a small, partial test of it, this presentation of his situational action theory is restricted to only those portions of the theory which the present study does address (for more complete presentations of Wikström's situational action theory see Wikström 2004; 2006; 2010a; 2010b).

In situational action theory, offending is the result of individuals placed in a situation in which they perceive various alternatives for action, make choices among 
these alternatives, and act upon these choices. Wikström (2010a) regards perceptions as the key element in the perception-choice linkage, for if a behavior is not perceived to be among the available alternatives, the behavior cannot be chosen. Conversely, if a behavior is perceived as an available alternative, then it may be consider and possibly selected. Thus, if an individual does not perceive offending as an available option, then elements of rational decision-making (choice) such as perceptual deterrence are irrelevant.

For Wikström, one of the primary elements by which individuals may perceive offending as an available alternative is their level of personal morality, that is, the degree to which they hold moral proscriptions against the behavior. Those with strong moral proscriptions cannot perceive of offending as an available alternative. Those with weaker levels of personal morality can conceive of offending as among their behavioral options and are free to consider it.

Individuals whose personal morality permits them to perceive of offending as a viable option must then decide whether or not to make such a behavioral choice. Key among the factors in this choice process is the components of perceptual deterrence. If a situation in which offending is perceived to be an available alternative, is deemed to be too risky (i.e., the likelihood of getting caught is too high), then the individual will be deterred from offending. Conversely, if the risks are minor, then the individual will choose to offend.

Based upon these propositions derived from Wikström's situational action theory, Svensson (2015: 5) hypothesized that there is an interaction effect between personal morality and perceptual deterrence, such that the effects of perceptual deterrence on offending should be strongest where personal morality is weakest. Svensson's (2015) test of this hypothesis supported it. So too have studies by Pauwels, Weerman, Bruinsma, \& Bernasco (2011), Wikström, Tseloni, and Karlis (2011), and several early studies (Bachman, Paternoster, and Ward 1992; Burkett and Ward 1993; Paternoster and Simpson 1996; but c.f., Gallupe and Baron 2014; Grasmick and Green 1981, and Jensen, Erickson, and Gibbs 1978). Supportive studies tend to be based on European samples or to involve measures of respondents' inclinations to commit offenses in the future. Conversely, studies which have failed to observe a morality* perceptual deterrence interaction are typically based on US samples. The present study attempts to replicate Svensson (2015) by testing his personal morality* ${ }^{*}$ erceptual deterrence interaction hypothesis against self-reported survey data on academic dishonesty from a sample of college students and making use of cheating-specific indicators of personal morality and perceptual deterrence.

\section{METHODS}

The data for this study were derived from a nonrandom sample of adult (i.e., 18 years of age or older) undergraduate students enrolled in all upper-division sociology classes at a large public university located in the southwestern region of the United States. All undergraduate students enrolled at this university at the time of this data collection were required to take twelve credit-hours of upper-division electives. Because most upper-division sociology courses, unlike other courses in the College of Arts and Sciences at this university, did not require any prerequisites, these courses were open to any students needing to fulfill their upper-division elective requirement. This, in addition to the fact that these courses address highly relevant and interesting social issues like marriage and family, crime and justice, race and gender, and so on, made them especially appealing to a large proportion of the student body. As such, this sample was fairly representative of undergraduate students within the College of Arts and Sciences at the university during the semester in which these data were collected. The sample is about 52 percent female, 24 percent minority, and 58 percent junior/senior status.

The research was conducted through the use of a self-administered questionnaire requiring approximately thirty to forty-five minutes to complete. Participation in the study was voluntary and both the anonymity of the respondents and the confidentiality of their responses were strictly guaranteed. Moreover, signed, informed consent was obtained prior to the administration of the questionnaire and prior approval for the study was obtained by the university's Institutional Review Board.

The survey was given to all students attending each upper-division sociology class offered during a single academic semester for which the collection of these data were permitted. The total unique enrollment (i.e., no student counted more than once) in all these classes was 732 , but only 448 usable surveys were obtained. The rather low response rate (61 percent) was attributed to a combination of absenteeism, incomplete surveys, ineligibility of minor students, and 
students' decisions not to participate. Nonetheless, this response rate is similar to those reported in other studies using similar techniques with college samples (Gibbs and Giever 1995; Lanza-Kaduce 1988).

\section{Dependent Variable: Academic Dishonesty}

This study employs a measure of academic dishonesty as the dependent variable. Academic dishonesty is defined as using deceit (fraud) in academic work. It is clearly a form of deviant behavior but it is also a form of "analogous" non-criminal behavior; an act of fraud undertaken in pursuit of selfinterest (Gottfredson and Hirschi 1990) and thus, is suitable for testing Wikström's situational action theory (2004). Forms of academic dishonesty include cheating during an exam or on a homework assignment, paying for or being paid for cheating, plagiarism, lying about academic work, etc. All of these items are expressly prohibited under the university's code of student conduct and some (i.e., those involving the theft or destruction of property, including intellectual property) could be prosecuted as felonies or misdemeanors under the state's criminal law. Moreover, Wikström (2007, p.12) goes to some length to explain that (a) crimes "are acts that breach moral rules of conduct stated in law;" "to explain acts of crime we thus need to explain why people ... breach moral rules;" hence, "explaining acts of crime is not different from explaining why people breach moral rules more generally." Therefore, the decision to test Wikström's theory with data on self-reported deviant behavior, in this case academic dishonesty among college students, is an appropriate vehicle for doing so.

Our measure is a composite of the frequency of six forms of self-reported academic dishonesty engaged in over the past twelve months: (a) looked at another student's answers during an exam, (b) plagiarized a term paper, (c) had another student take an exam for you, (d) got illicit, advance copies of an exam, (e) lied to a professor about missing an exam, and (f) falsified information on a research paper. The six items comprising this composite measure were operationally consistent with items in the "unethical academic behavior scale" developed by Calabrese and Cochran (1990). These items were each dichotomized to form prevalence scores for each item. The six dichotomous items were then summed to form a variety index of selfreported academic dishonesty (mean $=0.90$, std. dev. $=.98)$.

\section{Key Theoretical Variables: Personal Morality and Perceived Deterrence}

As a partial test of Wikström's situational action theory (2010a), this study addresses the proposed interactive effects of personal morality and perceptual deterrence on academic dishonesty. The measure of personal morality employed is a scale of respondents' attitudes toward academic dishonesty. Specifically, it is a six-item weighted, additive scale (alpha reliability of .85) comprised of student responses to the following Likert-type statements $(1=$ strongly disagree, $4=$ strongly agree): (a) "I feel that it would be wrong for me to cheat on an exam for any reason," (b) "I feel it would be okay for me to cheat on an exam that I didn't have time to study for (reverse coded)," (c) "I feel it would be okay to cheat if the professor had not done an adequate job of teaching the course (reverse coded)", (d) "I would turn-in anyone I knew was cheating," (e) "I would cheat to avoid getting a poor grade (reverse coded)," and (f) "I would not turn-in a close friend that I knew was cheating (reverse coded)." Prior to scaling these items were entered into a principal components analysis from which a single-factor solution best fit these data (factor loadings of .57 to .82 , and reproduced $69.3 \%$ of the variance among these items). The items were then weighted by their factor scores and summed together to obtain the attitudes toward academic dishonesty scale.

The perceived certainty of formal sanctions for acts of academic dishonesty was measured by a six-item scale that asked respondents, "Do you think you would get caught by your professors if you..." (a) cheated off another person's exam, (b) plagiarized a term paper, (c) had someone take an exam for you, (d) got copies of a test before taking it, (e) lied to a professor about missing an exam, and ( $f$ ) falsified information on a research paper. Responses were fixed along a fourpoint ordinal scale ranging from $1=$ "definitely would not" to $4=$ "definitely would. These six items were entered into a principal components analysis from which a single-factor solution best fit these data (factor loadings of .69 to .76 , and reproduced $80.3 \%$ of the variance among these items). The items were then weighted by their factor scores and summed together; the weighted, additive scale produced had an internal consistency of .80 .

\section{Socio-Demographic Control Variables}

All analyses include controls for the effects of respondent's age (coded in years), sex ( $0=$ female, $1=$ 
male), race/ethnicity (dummy variables for White, Black, and Hispanic, with other races as the omitted category) and grade point average (0.00 - 4.00). Also included are controls for the level of education attained by the respondent's head of household (a seven-point ordinal scale variable $1=$ grade school, $7=$ advanced degree), a twelve-point ordinal measure of the respondent's estimate of their family's annual income 1 $=$ under $\$ 5000,12=\$ 100,000$ or more), and the kind of community in which they were raised $(1=$ rural area, under 2,000 pop., 7 = large city, more than 250,000 pop.). Table 1 presents descriptive statistics for each of the variables employed in the analyses.

\section{Method of Analysis}

Given that the dependent variable is a count of the number of different types of academic dishonesty the respondents report having engaged in over the past 12-months, and that this variable is overdispersed, negative binomial regression was use to examine the relative, independent effects of personal morality and perceived certainty of formal sanction threats. Four models were examined: one each for the direct effects of personal morality and perceptual deterrence (Models 1 and 2, respectively); a third model to examine the relative effects of these two key theoretical variables while controlling for the influence of one another; this model (Model 3) also permits an exploratory assessment of the extent to which the effects of one is potentially mediated or rendered spurious by the other; and a fourth model (Model 4) which includes a crossproduct term for the potential interactive effects of personal morality and perceptual deterrence; this model allows for an examination of the potential conditioning effects of one on the other. All four models include the socio-demographic variables as controls (only the parameter estimate for respondents' age attained statistical significance). Moreover, both the personal morality scale and the perceptual deterrence scale were transformed into z-scores (mean $=0$, std. dev. $=1$ ) before being entered into these models - this has the effect of mean centering the variables and avoiding any problem with multicollinearity among them and their cross-product term (Aiken and West 1991). Finally, because the academic dishonesty index is a count of the variety of the six different forms of cheating respondents' self-reported any involvement during the past 12-months and is overdispersed, negative binomial regression modeling is used (Tobit, Poisson, and standard OLS regression modeling were also employed and the findings were substantively similar to the negative binomial regressions results presented here.

\section{RESULTS}

Pearson zero-order product moment correlations among our three primary variables (i.e., academic dishonesty, personal morality, and perceived certainty

Table 1: Descriptive Statistics of Variables in Analyses $(N=448)$

\begin{tabular}{|c|c|c|c|}
\hline VARIABLE & DESCRIPTION & MEAN & STD. DEV. \\
\hline Academic Dishonesty & 6-item Variety Index & 0.90 & 0.98 \\
\hline $\begin{array}{c}\text { Personal Morality } \\
\text { (condemnation of cheating) }\end{array}$ & $\begin{array}{l}\text { 6-item weighted additive scale } \\
\text { (standardized into z-scores) }\end{array}$ & 0.00 & 1.00 \\
\hline $\begin{array}{l}\text { Perceived Certainty of Formal } \\
\text { Sanctions }\end{array}$ & $\begin{array}{l}\text { 6-item weight additive scale } \\
\text { (standardized into z-scores) }\end{array}$ & 0.00 & 1.00 \\
\hline Age & in years & 21.14 & 2.99 \\
\hline Sex & dummy variable ( $1=$ male) & 0.48 & 0.50 \\
\hline White & dummy variable ( $1=$ White) & 0.75 & 0.43 \\
\hline Black & dummy variable (1=Black) & 0.06 & 0.24 \\
\hline Hispanic & dummy variable (1=Hispanic) & 0.03 & 0.17 \\
\hline Grade Point Average & ratio variable ( 0.00 to 4.00$)$ & 2.93 & 0.53 \\
\hline Rural-Urban Residency & $\begin{array}{l}\text { 7-point ordinal scale } \\
\text { (1=rural to } 7=\text { large city })\end{array}$ & 4.88 & 1.90 \\
\hline $\mathrm{H}-\mathrm{O}-\mathrm{H}$ Education & $\begin{array}{l}\text { 7-point ordinal scale } \\
\text { (1=grade school to } 7=a d v \text {. degree) }\end{array}$ & 5.48 & 1.37 \\
\hline Family Income & $\begin{array}{c}\text { 12-point ordinal scale } \\
\text { (1=under } \$ 5 \mathrm{~K} \text { to } 12=\text { over } \$ 100 \mathrm{~K})\end{array}$ & 8.36 & 2.95 \\
\hline
\end{tabular}


of formal sanction threats) show that both personal morality and perceived formal sanction threats are significantly though modestly correlated with the frequency of academic dishonesty $(r=-.37, p<.001$ and $r=-.16, p<.001$ respectively). In addition, personal morality is also modestly associate with perceived formal sanction threats $(r=.20, p<.001)$. These correlations suggest tentative support for the hypotheses derived from Wikström's situational action theory (2004). In addition, they suggest little concern for problematic multicollinearity, a conclusion supported by the collinearity diagnostics generated from OLS regression analyses for which variance inflation factor scores never exceeded 1.46 .

Table 2 presents the findings from four negative binomial regression models. The first model (Model 1) confirms that the bivariate association between personal morality and academic dishonesty reported above continues to hold while controlling for the effects of a variety of socio-demographic characteristics of the respondents $(b=-.373, p<.001)$. Those with stronger morals against cheating report lower levels of academic dishonesty. This model accounts for approximately $16 \%$ of the variance in academic dishonesty.

Likewise, the bivariate association between the perceived certainty of formal sanctions for cheating and academic dishonesty is also affirmed while controlling for the influence of the socio-demographic variables (b $=-.217, p<.01-$ see Model 2 ). However, this model accounts for only about $7 \%$ of the variance in academic dishonesty.
Model 3 examines the relative effects of both personal morality and perceived formal sanction threats on academic dishonesty while controlling for the rival effects of one another and the social-demographic variables. While the effect of personal morality on academic dishonesty is relatively undiminished once perceived sanction threats are added to the equation ( $b$ $=-.352, p<.001-$ compare Model 3 with Model 1 ), the effect of perceived certainty of formal sanctions on academic dishonesty is reduced by more than a fourth once the effect of personal morality is controlled $(b=-$ $.161, p<.01$-- compare effects reported in Model 3 with those in Model 2). This suggests that a considerable portion of the effect of formal sanction threats on cheating may be either mediated by or is spurious due to personal morality; longitudinal data and formal tests for mediation are necessary to determine which of these two possibilities is best supported by the evidence. In addition, adding the perceived formal sanction threat is variable to the model increased the explained variance by less than 0.5 percent.

Finally, Model 4 reports the interactive effects of personal morality and the perceived certainty of formal sanction threats on academic dishonesty by adding their cross-product as a term in the regression equation. The direct, relative effects of both personal morality $(b=-.357, p<.001)$ and perceived certainty of formal sanctions $(b=-.169, p<.01)$ on academic dishonesty are retained once this cross-product term is added to the equation. However, it is clear that personal morality does not condition the effect of perceived sanction threats $(b=-.036, p=.49)$ as argued in Wikström's situational action theory.

Table 2: Negative Binomial Regression Models Regarding the Effects of Morality and Formal Deterrence on Academic Dishonesty (Standard Errors in Parentheses)

\begin{tabular}{|c|c|c|c|c|}
\hline Independent & Model 1 & Model 2 & Model 3 & Model 4 \\
\hline \multicolumn{5}{|l|}{ Variables: } \\
\hline Morality & $\begin{array}{c}-.373^{\star * *} \\
(.048)\end{array}$ & & $\begin{array}{c}-.352^{\star \star *} \\
(.049)\end{array}$ & $\begin{array}{c}-.357^{\star * *} \\
(.049)\end{array}$ \\
\hline Certainty & & $\begin{array}{l}-.217^{* *} \\
(.055)\end{array}$ & $\begin{array}{l}-.161^{* *} \\
(.055)\end{array}$ & $\begin{array}{l}-.169^{* *} \\
(.056)\end{array}$ \\
\hline $\begin{array}{l}\text { Morality* } \\
\text { Certainty }\end{array}$ & & & & $\begin{array}{l}-.036 \\
(.054)\end{array}$ \\
\hline Intercept & 1.564 & 2.330 & 1.681 & 1.705 \\
\hline $\mathrm{R}^{2}$ & .163 & .072 & .167 & .178 \\
\hline
\end{tabular}

NOTE: All models control for the effects of respondents' age, sex, race/ethnicity, grade point average, urban residency, family income, and head of household's level of educational attainment; however, only the effect respondents' age attained statistical significance. ${ }^{*} p<.05,{ }^{\star \star} p<.01,{ }^{* *} p<.001$ (one-tailed). 


\section{DISCUSSION}

Based on Wikström's situational action theory (2010a), Svensson (2015) hypothesized that deterrence and morality interact to explain offending; specifically, the perceived certainty of getting caught is expected to have a stronger effect on offending among persons with low levels of personal morality than among those with high levels of personal morality. Persons high in personal morality are presumed to be unable to perceive offending as an available alternative course of action in a particular situation and, therefore, do not engage in any rational calculation of the odds and costs of getting caught. Conversely, persons low in personal morality can perceive of offending as a viable course of action, but before choose such a course of action, must first assess the possible odds and costs of getting caught. Hence, those low in personal morality are free to consider offending as an available option and, thus, are, able to be deterred by sanction threats. Svensson (2015) used self-report data from a sample of Swedish adolescents and found support for this hypothesis. That is, he found a strong interaction effect between perceptual deterrence and personal morality on offending, such that the effect of perceptual deterrence on offending was stronger among those low in personal morality. This observation is consistent with the theoretical expectations of Wikström's situational action theory (2010a) and is also consistent with other studies (Paternoster and Simpson 1996; Wikström, Tseloni, and Karlis 2011).

The present study attempted to replicate Svensson (2015) using self-report data on academic dishonesty among a sample of American college students, and behavior-specific indicators of both personal morality and perceptual deterrence. The present study found no evidence of an interaction effect between perceptual deterrence and personal morality on academic dishonesty. While such an observation is inconsistent with both Svensson (2015) and Wikström's situational action theory; it is consistent with other studies (Gallupe and Baron 2014; Grasmick and Green 1981; Jensen, Erickson, and Gibbs 1978).

The findings of the present study suggest that personal morality and perceptual deterrence have additive, but not multiplicative effects on college student cheating behavior. In relation to the small but growing body of research literature on this issue, the present study does little to clarify the situation. Some tests of situational action theory observe the hypothesized interaction between morality and deterrence (Pauwels et al. 2011; Svensson 2015; Wikström et al. 2011). These findings are shared by some earlier studies that predate Wikström's theory (Bachman et al. 1992; Burkett and Ward 1993; Paternoster and Simpson 1996). However, other studies, both tests of situational action theory and studies that predate it fail to observe any conditioning influence of personal morality on the effects of perceptual deterrence on offending behavior (Gallupe and Baron 2014; Grasmick and Green 1981; Jensen et al. 1978). Two characteristics of studies supportive of this morality*deterrence interaction stand out. Firstly, all studies testing situational action theory with non-US samples find support for the morality*deterrence interaction; all of the non-supportive studies, including the present study, were based on US samples. Secondly, most of the studies using a measure of respondents' inclination to engage in future offending are supportive of this interaction effects (see Bachman et al. 1992 and Paternoster and Simpson 1996; c.f., Grasmick and Green 1981).

Perhaps there are other reasons for the mixed, unstable findings in this area such as differences in the form (non-criminal or minor delinquency and drug use versus serious offending) and measurement of offending used (prevalence or frequency measures versus variety indexes); or perhaps the unstable body of findings is due to differences in the method of statistical modeling employed (OLS regression versus Tobit, Poisson, or negative binomial regression). Perhaps the mixed findings are due to other differences in sampling, or in the measurement of the morality and/or perceptual deterrence. There could be a host of reasons, but the present state of the theory, at least with regards to the hypothesized interaction effects between personal morality and perceptual deterrence on offending, is mixed and unstable. A similar observation regarding mixed, unstable effects could, perhaps, be made about other interaction effects derived from Wikström's situational action theory such as the expected interactions between personal morality and self-control (Gallupe and Baron 2014; Svensson, Pauwels, and Weerman 2010; Wikström and Svensson 2010) or between self-control and perceptual deterrence (Cochran, Aleksa and Sanders 2008; Sellers 1999; Wright, Caspi, Moffitt, and Paternoster 2004).

There are at least five rather obvious limitations to this study which future efforts should attempt to address. First, the study is admittedly a very incomplete, partial test of Wikström's situational action 
theory. However, it is no less complete than other studies available in the extant literature and, importantly, a full or even more complete test of Wikström's situational action theory is well beyond the capacity of most, if not all, existing data sets. Second the study is based on a sample of college students enrolled at a single public university. Such a narrow and non-random sample has extremely limited external generalizability. Again, however, this is also true of some of the other studies in this area of inquiry (c.f., Svensson 2015; Pauwels, et al. 2011). Thirdly, the data are cross-sectional, a problem shared with most of the other studies in this line of inquiry, but makes it impossible to tease out the causal ordering of effects does personal morality influence behavior or does behavior influence morality? Fourth, the study examines academic dishonesty, perhaps a rather minor form of offending. However, it shares similarities to Paternoster and Simpson's (1996) study of corporate crime; in addition some forms of academic dishonesty are crimes in the state from which these data were collected and are treated as seriously as many of the forms of offending examined in many of the other studies; finally, sanctions for cheating, even if extralegal, can be as potentially life changing as the legal sanction for the crimes studies by others. Perhaps the greatest limitation to this study, as well as to others, is the decontextualized or non-situation specific nature the data. The perception-choice process in Wikström's situational action theory is situation-specific. Future studies should pay careful attention to address each of these limitations, but especially the need for situationspecific indicators of perception and choice.

\section{REFERENCES}

Aiken, Leona S. and Stephen G. West. 1991. Multiple Regression: Testing and Interpreting Interactions. Newbury Park, CA: Sage.

Bachman, Ronet, Raymond Paternoster, and Sally Ward. 1992. "The Rationality of Sexual Offending: Testing a Deterrence/ Rational Choice Conception of Sexual Assault." Law and Society Review, 29(3): 343-374.

http://dx.doi.org/10.2307/3053901

Burkett, Steven R. and Sally Ward. 1992. "A Research Note on Perceptual Deterrence, Religiously Based Moral Condemnation, and Social Control." Criminology, 3(1):119-134.

Calabrese, Raymond L. and John K. Cochran. 1990. "The Relationship of Alienation to Cheating among a Sample of American Adolescents." Journal of Research and Development in Education, 23(1): 65-72.

Cochran, John K., Valantina Aleksa, and Beth Sanders. 2008. "Are Persons Low in Self-control Rational and Deterrable?" Deviant Behavior, 29(4): 461-483.

http://dx.doi.org/10.1080/01639620701598148

Gallupe, Owen and Stephen W. Baron. 2014. "Morality, Self-control, Deterrence, and Drug Use: Street Youths and Situational Action Theory." Crime and Delinquency, 60(2):284-305. http://dx.doi.org/10.1177/0011128709359661
Gibbs, John J. and Dennis Giever. 1995. "Self-control and Its Manifestation among University Students: An Empirical Test of Gottfredson and Hirschi's General Theory of Crime." Justice Quarterly, 12(2): 231-255.

http://dx.doi.org/10.1080/07418829500092661

Gottfreedson, Michael and Travis Hirschi. 1990. A General Theory of Crime. Stanford, CA: Stanford University Press.

Grasmick, Harold. R. and Donald E. Green. 1981. "Deterrence and the Morally Committed." Sociological Quarterly, 22(1): 1-14. http://dx.doi.org/10.1111/j.1533-8525.1981.tb02204.x

Jensen, Gary F., Maynard L. Erickson, and Jack P. Gibbs. 1978. "Perceived Risk of Punishment and Self-reported Delinquency." Social Forces, 57(1): 57-78. http://dx.doi.org/10.1093/sf/57.1.57

Lanza-Kaduce, Lonn. 1988. "Perceptual Deterrence and Drinking and Driving among College Students. Criminology, 26(2): 321-341.

http://dx.doi.org/10.1111/j.1745-9125.1988.tb00844.x

Paternoster, Raymond and Sally Simpson. 1996. "Sanction Threats and Appeals to Morality: Testing a Rational Choice Model of Corporate Crime." Law and Society Review, 30(4): 859-866. http://dx.doi.org/10.2307/3054128

Pauwles, Lieven., Frank Weerman, Gerben Bruinsma, and Wim Bernasco. 2011. "Perceived Sanction Risk, Individual Propensity and Adolescent Offending: Assessing Key Findings from the Deterrence Literature in a Dutch Sample." European Journal of Criminology, 8(5):386-400. http://dx.doi.org/10.1177/1477370811415762

Pratt, Travis C., Francis T. Cullen, Kristie R. Blevins, Leah E. Daigel, and Tamara D. Madensen. 2006. "The Empirical Status of Deterrence Theory: A Meta-analysis." Pp. 367-396 in Taking Stock: the Status of Criminological Theory, Advances in Criminological Theory, Vol. 15, edited by F. T. Cullen, J.P. Wright, and K. R. Blevins. New Brunswick, NJ: Transaction Publishing.

Sellers, Christine S. 1999. "Self-control and Intimate Violence: An Examination of the Scope and Specification of the General Theory of Crime." Criminology, 37(2): 375-404. http://dx.doi.org/10.1111/j.1745-9125.1999.tb00490.x

Svenson, Robert. 2015. "An Examination of the Interaction between Morality and Deterrence in Offending: A Research Note." Crime and Delinquency, 6(1): 3-18. http://dx.doi.org/10.1177/0011128713486068

Svensson, Robert, Lieven Pauwels, and Frank M. Weerman. 2010. "Does the Effect of Self-control on Adolescent Offending Vary by Level of Morality?" Criminal Justice and Behavior, 37(6): 732-743.

http://dx.doi.org/10.1177/0093854810366542

Wikström, Per-Olaf H. 2004. "Crime as Alternative: Towards a Crosslevel Situational Action Theory of Crime Causation." Pp. 1-43 in Beyond Empiricism: Institutions and Intentions in the Study of Crime, Advances in Criminological Theory, Vol. 13, edited by J. McCord. New Brunswick, NJ: Transaction Publishing.

Wikström, Per-Olaf H. 2006. "Individuals, Settings, and Acts of Crime: Situational Mechanisms and the Explanation of Crime." Pp. 61-107 in The Explanation of Crime" Contexts, Mechanisms, and Development, edited by P-O. H. Wikström and R. J. Sampson. Cambridge, UK: Cambridge University Press.

Wikström, Per-Olaf H.(2007. "Deterrence and Deterrence Experiences: Preventing Crime through the Threat of Punishment." Pp. 345-378 in International Handbook of Penology and Criminal Justice, edited by S. G. Shoham, O. Beck, and M. Kett . Boca Raton, FL: CRC Press.

Wikström, Per-Olaf H. 2010a. "Situational Action Theory." Pp. 3-43 in Encyclopaedia of Criminological Theory, edited by F. T. Cullen and P. Wilcox. . Beverly Hills, CA: Sage Publications.

Wikström, Per-Olaf H. 2010b. "Explaining Crime as Moral Actions." Pp. 211-239 in Handbook of the Sociology of Morality, edited by S. Hitlin and S. Vaisey. New York: Springer Verlag. 
Wikström, Per-Olaf H. and Robert Svensson. 2010. "When Does Self-control Matter? The Interaction between Morality and Self-control in Crime Causation." European Journal of Criminology, 7(5): 395-410.

http://dx.doi.org/10.1177/1477370810372132

Wikström, Per-Olaf H., Andromachi Tseloni, and Dimitris Karlis. 2011. "Do People Comply by the Law because They Fear Getting Caught?" European Journal of Criminology, 8(5): 401-420.
Wright, Bradley R. E., Avsholom Caspi, Terrie Moffitt, T., and Ray Paternoster. 2004. "Does the Perceived Risk of Punishment Deter Criminally Prone Individuals? Rational Choice, Selfcontrol, and Crime." Journal of Research in Crime and Delinquency, 41(2): 180-213.

http://dx.doi.org/10.1177/0022427803260263

Received on 05-08-2015

Accepted on 17-08-2015

Published on 10-09-2015

DOI: http://dx.doi.org/10.6000/1929-4409.2015.04.19

(C) 2015 John K. Cochran; Licensee Lifescience Global.

This is an open access article licensed under the terms of the Creative Commons Attribution Non-Commercial License (http://creativecommons.org/licenses/by-nc/3.0/) which permits unrestricted, non-commercial use, distribution and reproduction in any medium, provided the work is properly cited. 